Espaço Aberto | Open Space

\title{
Comunicabilidad y mediatización de los discursos psicoanalíticos en Buenos Aires
}

Communicability and mediatization of psychoanalytic discourses in Buenos Aires

\author{
Xochitl Marsilli-Vargas' \\ https://orcid.org/0000-0001-9125-7191 \\ xmarsil@emory.edu \\ I Emory University - Atlanta, GA, Estados Unidos
}




\title{
Resumen
}

En este artículo analizo la circulación de discursos psicoanalíticos fuera de la clínica a través de algunos de sus canales mediáticos más cotidianos y masivos. Para ello utilizo el concepto de comunicabilidad (Briggs; Hallin 2007), que ilumina cómo se difunden los discursos a través de ideologías desarrolladas históricamente, y de mediatización (Agha, 2011), que designa la amalgama que se forma entre procesos comunicativos y su mercantilización. El análisis se centra en tres medios: humor gráfico, programas de televisióny anuncios publicitarios que circulan en la ciudad de Buenos Aires. Un argumento clave del análisis es que la escucha psicoanalítica juega un papel importante en la diseminación y reproducción en la esfera pública de discursos psicoanalíticos a través de la recepción y continuo reciclaje de estos discursos por parte del público lego.

Palabras clave: psicoanálisis; comunicabilidad; mediatización; escucha.

\begin{abstract}
In this article I analyze the circulation of psychoanalytic discourses beyond the clinic through some of its most popular media representations. To do so, I use the concept of communicability (Briggs; Hallin 2007), which help us understand the way in which discourses are disseminated through ideological channels, and mediatization (Agha, 2011), which designates the amalgam formed between communicative processes and their commodification. The analysis focuses on three media forms: graphic humor, television programs, and advertisements circulating in the city of Buenos Aires. A key argument of the analysis is that psychoanalytic listening plays an important role in the dissemination and reproduction in the public sphere of psychoanalytic discourses through their reception and continuous recycling by lay audiences.
\end{abstract}

Keywords: psychoanalysis; communicability; mediatization; listening. 
¿Cómo circula el psicoanálisis fuera de la clínica?, y ¿qué significados tiene en la cultura? En este artículo analizo la circulación de representaciones culturales del psicoanálisis en humor gráfico, programas de televisión y anuncios comerciales. El objetivo es mostrar cómo el público lego de Buenos Aires está expuesto al psicoanálisis como marco de interpretación y cómo la escucha psicoanalítica se reproduce en estos medios. Los conceptos principales de mi análisis son la mediatización, el vínculo entre prácticas institucionales y procesos de comunicación y mercantilización (Agha, 2011) y la comunicabilidad, el modo en que los discursos se difunden a través de canales ideológicos (Briggs; Hallin, 2007).

A cualquiera que haya estado un tiempo largo en Argentina le resultaría difícil pasar por alto el hecho de que los discursos psicoanalíticos circulan en varios medios de comunicación. Hay una cantidad de programas de televisión y de radio que involucran directa o indirectamente la teoría psicoanalítica, usando ideas y marcos teóricos psicoanalíticos para explicar diversas clases de fenómenos. Muchos programas presentan a analistas que discuten una variedad de temas que abarcan desde intercambios de tuits entre políticos y preguntas personales sobre la vida privada del conductor del programa, hasta el comportamiento de los famosos. En ocasiones, son llamados para discutir grandes preguntas: ¿Qué es el amor? ¿Qué es la soledad? Y la que se repite con más frecuencia: ¿Qué nos pasa a los argentinos?

La variedad de formatos y contenidos televisivos es notable. Hay entrevistas individuales (Animales sueltos, El ángel de la medianoche, Tiene la palabra, para nombrar solo algunos) en las que la o el conductor simplemente pregunta y la o el analista responde, apelando explícitamente a la teoría psicoanalítica. El analista despliega su pericia planteando la teoría del deseo de Lacan o la conceptualización del superyó de Freud, utilizando ejemplos de su práctica privada. El tono de estas entrevistas se hace eco de materiales de autoayuda que tienen como objetivo la autosuperación o el mejoramiento de sí mismo, aconsejando acerca de cómo lidiar con problemas emocionales personales. También tienden a hacer generalizaciones colosales sobre diferentes grupos demográficos, como cuando afirman que los hombres son mucho más fetichistas que las mujeres poniendo como ejemplo el hecho de que las mujeres compran ropa interior "sexy" para satisfacer el fetiche 
masculino. ${ }^{1}$ Otros programas (Cortá por Lozano, Pura química, Políticos al diván) invitan a analistas o tienen conductores que son ellos mismos analistas, para "psicoanalizar" a personas famosas. Esto puede consistir en "analizar" a las personas en vivo en televisión: una persona famosa se sienta o se recuesta en un sillón y la psicoanalista le hace preguntas e interpreta sus respuestas utilizando teoría psicoanalítica. Estos programas presentan a veces fragmentos breves de videos de famosos hablando y luego a los analistas haciendo juicios de valor e interpretando lo que dijeron ("lo que en realidad quieren decir es...").

Los discursos psicoanalíticos están mediados por un consumo público amplio. Programas de radio como Radio Lacan, Programa Radial Psi o Freudiana Radio: La voz psicoanalítica del mundo también presentan entrevistas individuales siguiendo un formato similar al televisivo. Pueden girar alrededor de una discusión sobre la diferencia entre neurosis y psicosis, o relacionar el estadio del espejo de Lacan con el comportamiento compulsivo en los adolescentes. También hay programas que incorporan la participación de oyentes que llaman al estudio y piden consejo y asesoramiento terapéutico. Al ser una experiencia de escucha por antonomasia, los programas de radio hacen hincapié en la importancia de escuchar y dirigen la atención de la audiencia hacia determinadas palabras o conceptos. También los interrogan acerca de qué "invocan" esas palabras en ellos, desplazando la denotación en favor de una interpretación hermenéutica.

La figura del analista es tan omnipresente en Argentina que funciona incluso como personaje publicitario para vender productos. Los comerciales hacen uso del estereotipo del analista como un hombre barbado, bien vestido, de unos 50 años, en una oficina agradable. Como veremos más adelante, esta figura es utilizada para vender diversos productos, desde cerveza hasta papas fritas, servicios de taller automotriz y aperitivos.

El psicoanálisis también aparece en el humor gráfico, que tiene una presencia de larga data en la cultura argentina. En tres de los periódicos de mayor circulación en Argentina, Clarín, La Nación y Página/12, los humoristas gráficos representan constantemente situaciones humorísticas utilizando el encuentro

1 Esto es lo que Gabriel Rolón le dijo a Alejandro Fantino en el programa Animales sueltos emitido el 6 de agosto de 2018 (cf. Rolon, 2018). 
analítico: una o un analizante en el diván y una o un analista sentado, anotador y lapicera en mano. Algunas de estas tiras cómicas son representaciones alegóricas de la sesión de análisis: el humorista gráfico Tute presenta a un hombre acostado en el diván, con un enorme globo encima de él que contiene un garabato enmarañado, mientras el analista, sentado en su silla, atrapa una línea del garabato para, presumiblemente, comenzar a desenredar el caos (figura 1). Analistas y analizantes abordan los temas a través de la conversación. Por ejemplo, el humorista gráfico Sendra representa a un hombre que le dice a su analista: "Doctor... las mujeres me asustan"; el analista responde, "Bueno... revisemos su infancia” y el hombre responde, “¿Y si se entera mi vieja?” (figura 2).

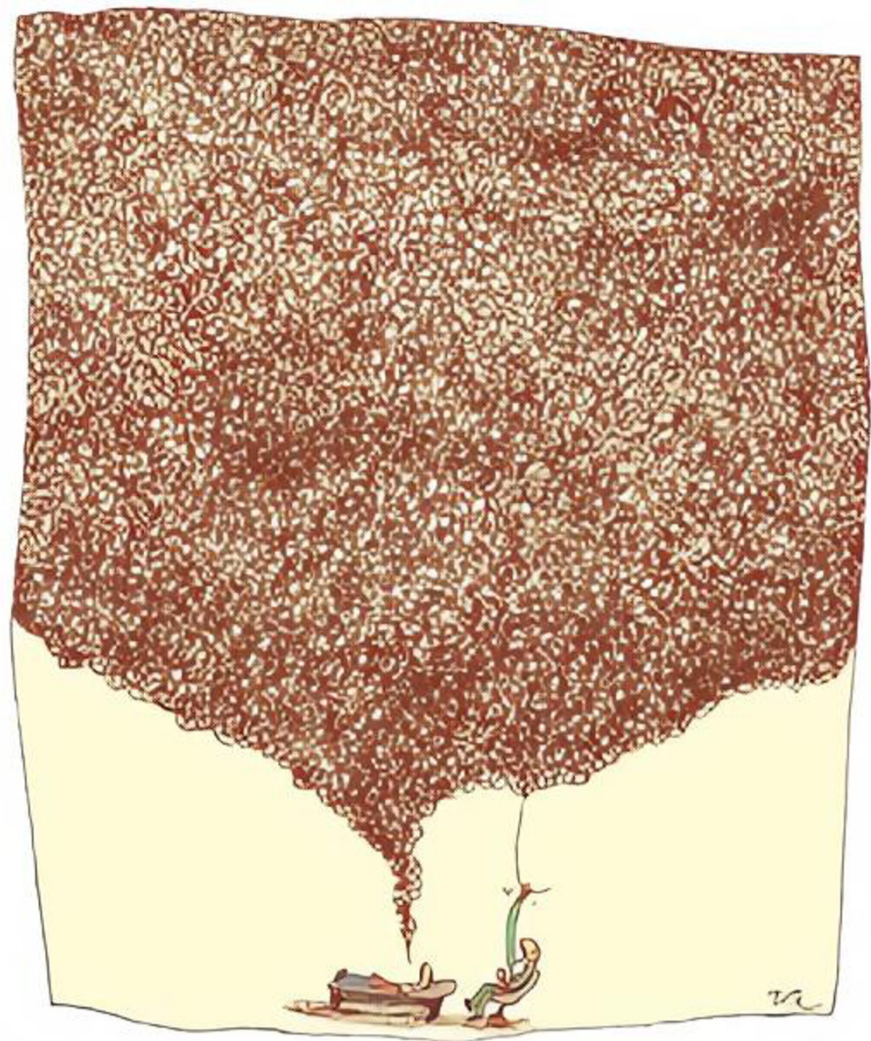

Figura 1. 


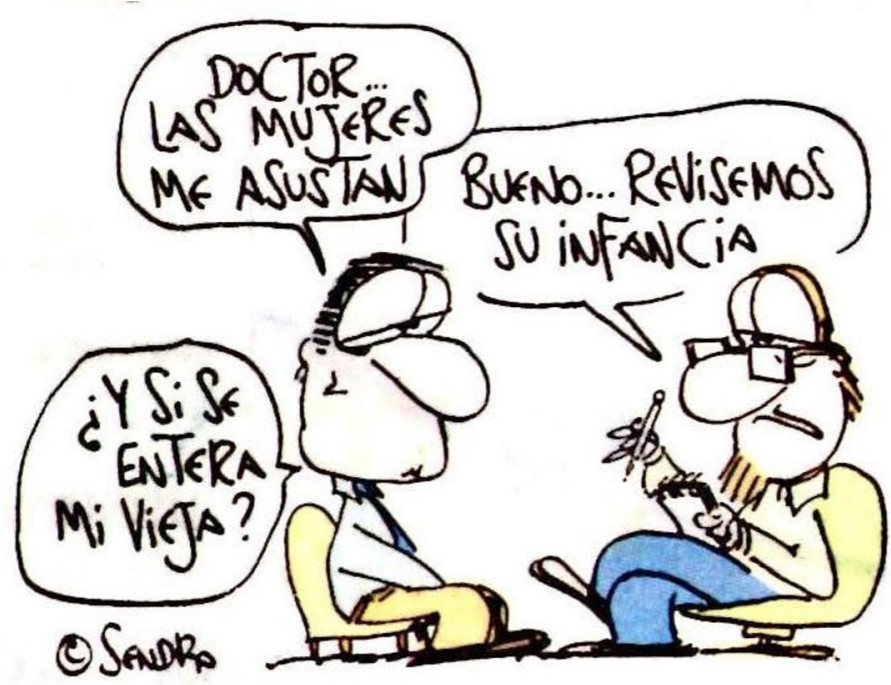

Figura 2.

La mayoría de los periódicos incluyen también columnas escritas por psicoanalistas y psicólogas/os, ya sea sobre teoría psicoanalítica o utilizando marcos psicoanalíticos para discutir cuestiones políticas. El 15 de agosto de 2019, por ejemplo, la sección semanal de psicología de Página/12 incluyó una nota titulada "El ejército de ocupación: Una mirada psicoanalítica sobre la saturación de agentes uniformados en el espacio público" (Rodríguez, 2019). Aquí, Cristian Rodríguez, un psicoanalista de Buenos Aires, describe los paralelismos entre la reciente proliferación de chalecos azules y amarillos utilizados por la policía de tránsito de la ciudad y la militarización de Buenos Aires durante la dictadura de los años 1970. Utilizando conceptos como "transubjetividad" y "represión psíquica funcional", Rodríguez se embarca en un análisis metafórico y psicoanalítico de los chalecos, revelando cómo estos despiertan recuerdos reprimidos de la militarización urbana. En 2019, Clarín, el diario de mayor difusión, publicó en su sección de psicología el artículo "Aplicá el método Marie Kondo para ordenar tu vida y tus vínculos. El psicólogo Alejandro Schujman y Laura Escobar, discípula de la japonesa, dan las claves para llevarlo al mundo interior" (Schujman, 2019). La palabra "vínculos" se refiere explícitamente al término psicoanalítico que describe el modo en que una persona se relaciona con otras 
estableciendo una estructura relacional. De este modo, el libro de Kondo -popular a nivel global por instar a sus lectores a ordenar sus casas para lograr ordenar sus vidas- es introducido en una conversación sobre teoría psicoanalítica.

Los ejemplos son infinitos, a lo largo y a lo ancho del espectro político. La Nación, un periódico conservador, tiene un canal en línea con una sección llamada Terapia de noticias, un programa semanal conducido por Diego Sehinkman, psicólogo y periodista. El semanario comienza con una viñeta sobre una discusión política en Argentina (por ejemplo, un senador que discute una política de gobierno), seguida por un monólogo de Sehinkman, en el que propone "diferentes lecturas" o "posibles escenarios" en relación con el significado del tema presentado. La palabra "terapia" en Terapia de noticias supone la idea de que hay muchas interpretaciones posibles de las cosas que dicen los políticos. La frase recurrente: “¿qué habrá querido decir?” resuena durante todo el programa. Desde 2012 Sehinkman ha escrito la sección semanal Políticos al diván, también en La Nación, donde en su rol de analista entrevista a políticos, replicando la sesión de análisis. En sus propias palabras, la entrevista busca emular "la primera sesión de terapia" y tomar "la mejor radiografía que se puede hacer de estos personajes" sin juzgar ni situarse uno mismo "desde un lugar moral". La metáfora de la radiografía conjura la noción de que hay algo escondido, listo para ser descubierto (cuando dices X, escucho Y). Que un programa como este sea producido por uno de los periódicos más importantes de Argentina y que políticos prominentes están dispuestos a participar, es un hecho notable. Sehinkman publicó en 2014 un libro basado en estas entrevistas (Sehinkman, 2014).

Fuera de los medios, el discurso psicoanalítico también tiene una fuerte presencia en aspectos centrales de la producción cultural argentina; el tango, por ejemplo, el género musical argentino por antonomasia, ilustra muy bien esto. Un grupo de psicólogos y bailarines de tango llamado Tango-Psi colocan al tango en conexión directa con el psicoanálisis. Mónica Peri, psicóloga y bailarina de tango afiliada a este grupo, escribió dos libros -Tango, un abrazo sanador (Peri, 2015) y PsicoTango: danza como terapia (Peri; Lavalle Cobo, 2010)- en los que dice haber encontrado un paralelismo freudiano entre el abrazo del baile del tango y "el primer abrazo que recibimos de nuestras madres". Sugiere que como el tango ha "demostrado ser un objeto del psicoanálisis, lo podemos cotejar a los juegos. En tanto juego la danza del tango nos permite ponernos en contacto con nuestro inconsciente. Cuerpos que hablan y son escuchados. 
Cuerpos encarnados, en los que se manifiesta la vida" (Peri, 2009, el subrayado es mío). La famosa ópera María de Buenos Aires, escrita en 1968 con música de Ástor Piazzolla -uno de los más célebres compositores argentinos de tango-, presenta la historia de María, una prostituta "nacida un día en que Dios estaba borracho", que muere y resucita como un fantasma. María deambula entonces por las calles, como un fantasma, y encuentra un singular circo regenteado por Los Analistas, en cuya arena los remordimientos, los complejos y las pesadillas son representados por acróbatas temerarios. Cuando uno de los acróbatas, Analista Primero, trata de interpretar el recuerdo de María de una sombra pero no lo logra, ella cree haber caído presa de una extraña locura.

La proliferación de representaciones culturales del psicoanálisis fuera de la clínica en Argentina también se extiende a las letras de rock, la astrología, el teatro, numerosos grupos de redes sociales y series televisivas, entre muchos otros. Aunque, como han argumentado el historiador Mariano Ben Plotkin y el antropólogo Nicolás Viotti (Plotkin; Viotti, 2020), el psicoanálisis como práctica clínica puede estar disminuyendo en Buenos Aires, lo que estos ejemplos sugieren es que la dialéctica entre la práctica clínica y su forma mercantilizada persiste. Estos y muchos otros programas de televisión y radio, columnas en periódicos y tiras cómicas continúan siendo producidos, sin signos evidentes de que el interés esté decayendo.

Este artículo analiza en detalle ejemplos de tres representaciones culturales: humor gráfico, psicoanalistas en televisión y publicidades. Estos ejemplos pueden ayudarnos a entender, primero, cómo estos discursos circulan fuera de la clínica, permeando la cultura popular; segundo, los mensajes metacomunicativos insertos en ciertas formas lingüísticas; y tercero, cómo la escucha psicoanalítica, en tanto género, está presente dentro de estas representaciones, facilitando la difusión de una ideología de la escucha según la cual hay un significado oculto dentro de los enunciados, disponible para ser interpretado (cuando dices $X$, escucho $Y$ ). Mi objetivo es mostrar el movimiento dialógico entre la constitución y la circulación de la escucha psicoanalítica, por un lado, y la producción cultural de discursos basados en el psicoanálisis por el otro.

Pero primero necesitamos entender cómo el psicoanálisis se convirtió en un marco de interpretación utilizable para otros propósitos. A continuación esbozo una breve historia de cómo las filosofías psicoanalíticas han permeado otros campos. 


\section{El psicoanálisis como marco interpretativo}

Casi desde sus comienzos el psicoanálisis ha abandonado la clínica y adquirido diferentes formas. Especialmente en la academia, conforme especialistas de las humanidades y las ciencias sociales comenzaron a analizar datos y textos y a crear teorías utilizando el así llamado marco psicoanalítico. Pero ¿qué parte del psicoanálisis ha migrado fuera de la clínica? ¿La información sobre el psicoanálisis y las teorías psicoanalíticas están disponible para cualquiera? ¿Qué significa el psicoanálisis en el contexto de esta amplia circulación?

En sus primeros días, el psicoanálisis tomó prestada terminología de la medicina. Esto sucedió no sólo como una búsqueda de prestigio para el psicoanálisis sino también porque muchos de los primeros analistas eran doctores (Balán, 1991; Frosh, 2010). La sala de consulta se transformó en el espacio clave del psicoanálisis porque era allí donde tenía lugar el tratamiento. La profesionalización del psicoanálisis siguió la estructura de la medicina (por ejemplo, se esperaba que las sesiones tuvieran determinada duración, el involucramiento emocional con la paciente era restringido, se asignaban lugares específicos al paciente/analizante y a la analista en el espacio de la sala de consulta, etc.). Como los psicoanalistas eran doctores que proporcionaban atención médica, la figura del psicoanalista se consolidó como la de un terapeuta (Roudinesco, 1990). En un sentido muy concreto, pues, la clínica terapéutica se volvió la fuente del psicoanálisis. y sus teorías y prácticas fueron desarrolladas para ser aplicadas dentro de la clínica (Dagfal, 2009; Frosh, 2010; Roudinesco, 1990, 2003). Sin embargo, con el tiempo, la "clínica" en el psicoanálisis fue extendiéndose más allá de su espacio físico original y se transformó en una metáfora.

Desde esta perspectiva, el psicoanálisis no es solo una ciencia médica, sino una práctica. Supone la presencia de un analista y un analizante; el objetivo del analizante es descubrir la fuente oculta (reprimida) de determinado mal o enfermedad y aprender a vivir una vida en la que su sufrimiento no necesariamente desaparezca, pero sí se mantenga a raya. El analista ayuda en este proceso a la vez como oyente y como testigo de la presencia del significado en aquello que para el analizante es indecible o no tiene sentido (Edelson, 1975). Este proceso sucede en un marco muy específico que involucra la transferencia (el modo inconsciente en el que un paciente se relaciona con o "usa" al analista para avanzar en su tratamiento), la contratransferencia (la respuesta del 
analista a la transferencia del paciente) y, lo más importante, la certeza de que en algún punto van a emerger los impulsos inconscientes.

Bajo esta definición, el psicoanálisis es un encuentro vivo que precisa de la interacción cara a cara para existir. Como dijo un experimentado analista en una de sus clases introductorias del primer año de "Psicopatología", en la Universidad de Buenos Aires (UBA): "Sin analista y paciente, estando juntos en su relación transferencial, la interpretación en sentido psicoanalítico no puede tener lugar". El punto es que, para tener una sesión de análisis, es necesario que estén presentes ciertos pasos y procesos muy específicos, de otra manera el psicoanálisis no tiene lugar y los procedimientos no son más que una conversación íntima con una persona amiga o conocida.

De acuerdo con el analista de la UBA, la ausencia del encuentro físico que define a la clínica, junto con sus especificidades teóricas, impide cualquier forma de hacer psicoanálisis. Stephen Frosh (2010, p. 4), uno de los más importantes historiadores del psicoanálisis, ha discutido detalladamente esta misma idea:

[C]uando el trabajo de un autor literario es interpretado en términos de trauma infantil, no es psicoanálisis; o cuando un comentarista político echa mano de ideas sobre los impulsos nacionales inconscientes, no es psicoanálisis; o cuando un psicólogo social o un filósofo utiliza la idea de intimidad y estabilidad de la autoestima para comprender conflictos de identidad, no es psicoanálisis. ${ }^{2}$

Frosh coincide con el profesor de la UBA y con muchos otros psicoanalistas en que lo que define al psicoanálisis es el encuentro terapéutico, que implica la copresencia de ambos, analizante y analista. ${ }^{3}$ Así, lo que sea que los teóricos sociales estén haciendo cuando utilizan explicaciones psicoanalíticas, no es

2 "[W]hen a literary author's work is interpreted in terms of childhood trauma, it is not psychoanalysis; or when a political commentator draws on ideas about unconscious national impulses, it is not psychoanalysis; or when a social psychologist philosopher uses the idea of intimacy and stability of selfhood to understand identity conflicts, it is not psychoanalysis."

3 Más recientemente, con la proliferación de las nuevas tecnologías mediáticas, las/os analistas están usando plataformas como Skype y WhatsApp para tener sesiones de análisis con pacientes que se encuentran fuera de su país de residencia. Transformando así la idea de que la copresencia es necesaria para el encuentro analítico. 
psicoanálisis. Lo que, en cambio, están haciendo es usar un marco particular para explicar una serie de diferentes fenómenos sociales.

Frosh atribuye la culpa de este abuso de las ideas psicoanalíticas a su creador mismo, Freud, y sus primeros discípulos, como Carl Jung. Freud publicó estudios sobre artistas creativos en los que utilizó el psicoanálisis para sacar a la luz aspectos de su psicología. ${ }^{4}$ En El malestar en la cultura Freud (1970) amplió su enfoque para abarcar a la sociedad en su conjunto, en un esfuerzo por tratar de darles sentido a las consecuencias desoladoras de la Primera Guerra Mundial. Esta flexibilidad está detrás de una variedad de usos del marco psicoanalítico entre las y los llamados teóricos posmodernos: los estudios feministas (Butler, 1990; Mitchell, 1974; Spivak, 1987), la teoría crítica (Adorno et al., 1967; Althusser; Balibar, 1971; Marcuse, 1955), la teoría del arte (Ogden, 1999), la literatura (Kristeva, 1984, 1987) y los estudios poscoloniales (Bhabha, 1991; Chakrabarty, 2000), entre muchos otros. Todos estos estudios utilizan aspectos particulares de diferentes escuelas de psicoanálisis para lograr diversos propósitos. ${ }^{5}$ Algunos/as analistas se han convertido en intelectuales públicos, generando capital cultural suficiente para representar una "autoridad cultural" (Zelizer, 1992) que les otorga el derecho de hablar sobre casi cualquier fenómeno cultural (Plotkin, 2017; Plotkin; Visacovsky, 2007).

La teoría psicoanalítica fue recogida de sus orígenes interaccionales e institucionales y transformada, entre otras prácticas, a través del proceso de entextualización, o "el proceso de hacer extraíble el discurso, de convertir un fragmento de producción lingüística en una unidad -texto-que debe ser abstraída de su situación interaccional" (Bauman; Briggs, 1990), ${ }^{6}$ y también mediante el proceso de contextualización, la reinserción de esos textos en un nuevo entorno institucional (Bauman; Briggs, 1990; Silverstein; Urban, 1996).

Entonces, ¿qué significa que el psicoanálisis en Argentina se ha trasladado más allá del espacio de la clínica, infiltrándose en contextos que no

4 Ver, por ejemplo, Un recuerdo infantil de Leonardo Da Vinci (Leonardo Da Vinci and a memory of his Childhood), de Freud (1964).

5 Un hecho importante a subrayar, ya que tanto la freudiana, la lacaniana, la kleiniana, la de Miller y la de Laplanche, así como otras escuelas psicoanalíticas varían mucho entre sí (ver Frosh, 1999; Gay, 1988; Stolorow, 2006).

6 "....] the process of rendering discourse extractable, of making a stretch of linguistic production into a unit-a text-that can be lifted out of its interactional setting" (Bauman; Briggs, 1990, p. 73). 
necesariamente obedecen a las configuraciones de la clínica? Lo que circula fuera de la clínica es un tipo de psicoanálisis entextualizado y mediatizado (Agha, 2011), la amalgama entre prácticas institucionales y procesos de comunicación y mercantilización, que adopta diferentes formas dependiendo de los diferentes contextos en que se lo haya situado (por ejemplo, la universidad, los programas de radio y televisión o las publicidades). En consecuencia, cuando escuchamos declaraciones como la de Yamil, un neuropsicólogo que afirma que el psicoanálisis está en todas partes en Argentina a causa de su "presencia hegemónica" en el sistema universitario nacional, lo que se ha vuelto ubicuo no es necesariamente la práctica clínica del psicoanálisis (aunque el número de personas que se analizan en Argentina es objetivamente muy alto en comparación con otros países), sino determinados textos descentrados de su origen interaccional e institucional y recentrados en diferentes contextos (Bauman; Briggs, 1990) a través de sus formas mediatizadas, que conectan aquellas prácticas institucionales con procesos de comunicación y mercantilización (Agha, 2011).

En la reproducción y la difusión de estos discursos hay un elemento clave: la escucha, denominador común que relaciona las diferentes modalidades del psicoanálisis fuera del ámbito de la clínica, una cualidad que he descrito con la fórmula cuando dices $X$ escucho $Y$. El género de escucha psicoanalítica está basado en creencia en lo inconsciente y en la capacidad de escucharlo, en busca de significados que están más allá de la comprensión del hablante (Marsilli-Vargas, 2014, 2016). A través de la escucha, resonancias de experiencias, sonidos y palabras producen en algún momento un referente, y entonces somos capaces de percibir el significado "real" de una experiencia particular.?

La mediatización del psicoanálisis surge de las acciones y los intercambios entre actores sociales. Los discursos del psicoanálisis en Argentina se basan en ideas social e históricamente específicas (por ejemplo, la idea de las prácticas inconscientes o el complejo de Edipo) que se reproducen y circulan como una serie de formas mediatizadas. En las secciones que siguen analizo detalladamente tres representaciones culturales del psicoanálisis en diferentes medios

$7 \quad$ El consumo del psicoanálisis en el ámbito de la clínica y en su forma mercantilizada (a través de la mediatización) están entrelazados en una relación dialéctica. Se alimentan mutuamente creando lo que Asif Agha llama (2011) "partículas semióticas", el rastro que forma una cadena semiótica donde es posible rastrear cómo los discursos son reciclados, que viajan a través de distintos medios y diferentes marcos de participación y prácticas culturales. 
masivos de comunicación, subrayando el rol crucial que juega la escucha en esta difusión.

\section{El psicoanálisis como práctica cultural}

Cuando los discursos del psicoanálisis son insertados en nuevos contextos, los límites entre el saber experto, la recepción masiva y la posterior reproducción de este saber se vuelven porosos, y los modos en que el psicoanálisis se practica, su habla y su escucha, atraviesan esos límites.

La exposición a los discursos psicoanalíticos crea un público lego con una tendencia a proporcionar libremente interpretaciones psicoanalíticas. Esta exposición puede ocurrir de modo directo, debido a que una persona asistió durante años a sesiones de psicoanálisis, o indirecto, por medio de información compartida por miembros de la familia o amigos que son analistas. La significativa presencia del psicoanálisis en los medios también ha contribuido a la creación de esta audiencia, haciendo que su marco interpretativo se convirtiera en parte relevante de la vida cultural y social de la ciudad de Buenos Aires. Si el psicoanálisis como modelo explicativo se ha vuelto socialmente relevante, es debido a la comunicabilidad de su forma textual.

Lo que está circulando no es "psicoanálisis" en sí mismo, sino un determinado discurso basado en la práctica del psicoanálisis. El concepto de "comunicabilidad" nos ayuda a entender ciertos discursos como efectivos, y por lo tanto contagiosos, porque se comunican exitosamente, mientras que otros no lo hacen. Como explica Charles Briggs (2007, p. 556), "la comunicabilidad sugiere locuacidad, la habilidad de ser fácilmente comunicado y entendido, y la capacidad que tienen los microbios de propagarse", agregando que "la comunicabilidad es infecciosa, el modo en que textos e ideologías encuentran audiencias y las sitúan socialmente y políticamente" (ver también Briggs, 2005). ${ }^{8}$ En el caso del psicoanálisis en Buenos Aires, tanto consumidores como productores de discursos basados en el psicoanálisis son responsables de su

8 "[...] communicability suggests volubility, the ability to be readily communicated and understood, and microbes' capacity to spread [...] communicability is infectious-the way texts and the ideologies find audiences and locate them socially/politically" (Briggs, 2007, p. 556). 
circulación y difusión, de manera que las fronteras entre el discurso psicoanalítico "autorizado" y su representación "no especializada" no son tan fijas como en los discursos biomédicos, donde por el contrario la ciencia aparece en respaldo de cualquier aseveración, como técnica consistente y confiable para el desarrollo de nuestra comprensión del mundo natural (Foucault, 2010; Latour, 1993, 2001, 2005).

A pesar de tener que ver con la salud y con la enfermedad, el psicoanálisis no convoca la misma legitimación conferida por la ciencia a los discursos biomédicos. El proceso para convertirse en analista no tiene una trayectoria bien definida a seguir; implica un proceso largo e idiosincrático en el que en muchos casos es la aspirante a analista quien se legitima a sí misma después de un largo compromiso personal con el análisis. En Francia el psicoanálisis goza de un alto prestigio cultural, pero no posee la legitimación social que se espera de una profesión universitaria (el título de psicoanalista no es reconocido por la universidad) (Lézé, 2006). La legitimación de los analistas no siempre está respaldada por una institución de enseñanza, y ello contribuye a diluir la diferencia entre analistas y legos. Semejante dilución de la expertise es un anatema en el terreno biomédico, donde la acreditación institucional garantiza a doctoras y doctores la autoridad de diagnosticar y prescribir medicación.

El hecho de que los conceptos psicoanalíticos estén tan alejados de la autoridad propia de los discursos de la biomedicina, en cierta medida, forma parte de su atractivo. Y pese a que en Argentina se han creado recientemente programas universitarios que confieren diplomas "legítimos" en psicoanálisis, el uso abundante del prefijo psi- (pisco-tango, música psico-trance), la presencia del psicoanálisis en múltiples campos de la producción cultural, y el percibido antiempirismo de algunos difusores del psicoanálisis, sugieren que los discursos psicoanalíticos son comunicables porque apelan a una cualidad universal de la humanidad relacionada con las emociones y los sentimientos personales, mediados por prácticas inconscientes.

\section{Humor gráfico}

El humor gráfico es útil para ver y comprender cómo los discursos psicoanalíticos y las representaciones de la escucha psicoanalítica circulan en Argentina. Un gran número de humoristas gráficos, algunos de los cuales tienen muchos 
seguidores a nivel internacional, incorporan en su obra conceptos psicoanalíticos. Además de una vasta cantidad de lectoras y lectores no especializados, las y los psicoanalistas también participan en la ecología de este medio -como artistas y como público lector-, acentuando la ambigüedad en relación con el lugar legítimo y auténtico de los discursos psicoanalíticos. No obstante, estas ambigüedades en relación con el lugar apropiado para los discursos psicoanalíticos contribuyen en definitiva a que los aspectos clave del discurso psicoanalítico y sus prácticas de escucha florezcan fuera del ámbito de la clínica.

Una ilustración de cómo los marcos psicoanalíticos son mediatizados en piezas de humor gráfico, y de las ambigüedades en relación con la autoridad del psicoanálisis en general en Argentina, puede verse en un evento que tuvo lugar en la Asociación Psicoanalítica Argentina (APA), en Buenos Aires. En 2017, Juan Matías Loiseau, famoso humorista gráfico argentino que publica bajo el nombre de Tute, publicó un libro llamado Humor al diván (Tute, 2017) y en el verano de 2018 la APA lo invitó a presentarlo en su sede. Por primera vez un humorista gráfico presentaba una obra en el elegante edificio de la calle Rodríguez Peña. Alicia Lagarrigue, directora de comunicaciones de la institución, explicó que decidió invitar a Tute porque "para mí, es el representante del psicoanálisis en todos nosotros".

El 12 de julio de 2018, el auditorio de la APA estaba repleto. Una heterogénea concurrencia compuesta por psicoanalistas, pero también por otros lectores se congregó para escuchar a Tute. Humor al diván es una colección de dibujos que representan momentos compartidos entre analista y analizante, historias breves de parejas y diálogos solitarios con la propia psiquis. El tema era un territorio familiar para Tute, quien ya había producido piezas relativas al psicoanálisis. Durante la presentación, le preguntaron por qué se había interesado tanto por el psicoanálisis. Pausada y cuidadosamente, Tute seleccionó sus palabras antes de responder:

Por un lado me interesa el psicoanálisis como técnica, me parece una técnica volada... O sea, creo que es una idea muy ingeniosa creada por un loco [risas]... Yo voy a análisis desde hace muchos años, así que empecé a aprender cosas, sólo como analizante, porque nunca lo estudié y no invierto en leer psicoanálisis. Pero me interesa. Desde el punto de vista humorístico, como humorista gráfico, también me parece súper interesante, es un espacio muy proclive al 
humor, ¿no? El pequeño sofá que es una especie de camita con un tipo sentado, y otro acostado, y no se conocen. Y, sin embargo, se cuentan... o al menos el analizante cuenta sus cosas más profundas, más íntimas, más miserables a un desconocido. Y se supone que se produce una cura con las pocas palabras que el otro sujeto -que de vez en cuando dice "Hmmm" [risas]-... Por otra parte, considero al psicoanalista un artista... Me hace gracia cuando [la gente] intenta llevar el psicoanálisis al terreno de una disciplina, como si fuera una ciencia exacta. Para mí está muy lejos, está mucho más cerca del campo artístico que de la ciencia. ${ }^{9}$

Sentados junto a Tute, los miembros del panel, figuras distinguidas del campo, ponían de relieve que la APA consideraba este evento como un acontecimiento importante en la institución. Uno de ellos era un famoso analista, el Doctor Andrés Rascovsky, ex presidente de la APA e hijo de Arnaldo Rascovsky, uno de los fundadores y principales difusores del psicoanálisis en Argentina. ${ }^{10}$ La otra moderadora era la psicóloga Liliana Pedrón, miembro activo tanto de la APA como de la Asociación Psicoanalítica Internacional (IPA, por sus siglas en inglés: International Psychoanalytic Association), coordinadora editorial del Journal of Psychoanalysis Today (un periódico en línea producido por la IPA) y coordinadora de eventos culturales y simposios relacionados con la APA.

Lejos de ser solo una celebración del valor artístico del libro, la discusión se centró en el análisis psicoanalítico de muchas cuestiones relativas a la obra y su autor. Por ejemplo, utilizando un marco psicoanalítico, Rascovsky abordó el tema del padre en la obra de Tute, señalando que ambos -tanto él como Tutesiguieron los pasos de las exitosas carreras de sus padres (Caloi, el padre de Tute, fue también un famoso humorista gráfico). Sus comentarios exploraban la continuidad de los vínculos subjetivos establecidos entre padre e hijo. De modo similar, Pedrón propuso un marco psicoanalítico, la búsqueda de "aquello que no fue dicho (dibujado)" en cada viñeta. Especuló acerca del significado

9 Presentación del libro Humor al diván en la APA, el 12 de julio de 2018. Para ver la entrevista: Tute en APA (2018).

10 Arnaldo Rascovsky organizó junto con Ángel Garma el "Congreso de Medicina Psicosomática", y en 1960 fue miembro fundador de la Federación Psicoanalítica de América Latina (FEPAL). 
de algunos dibujos, preguntándose si la "piedra flotante" (un dibujo de la luna, una constante en muchas de las historietas de Tute) acaso representa la culpa (figura 3). Pedrón comentó el hecho de que en algunas viñetas Tute tacha palabras y las reemplaza con otras nuevas, lo que la llevó a preguntarse si esto se debe a que las dibujó en forma apresurada, o si hay otro motivo. Advirtió que, para los psicoanalistas, la palabra tachada amenaza con anular el efecto de la nueva palabra.

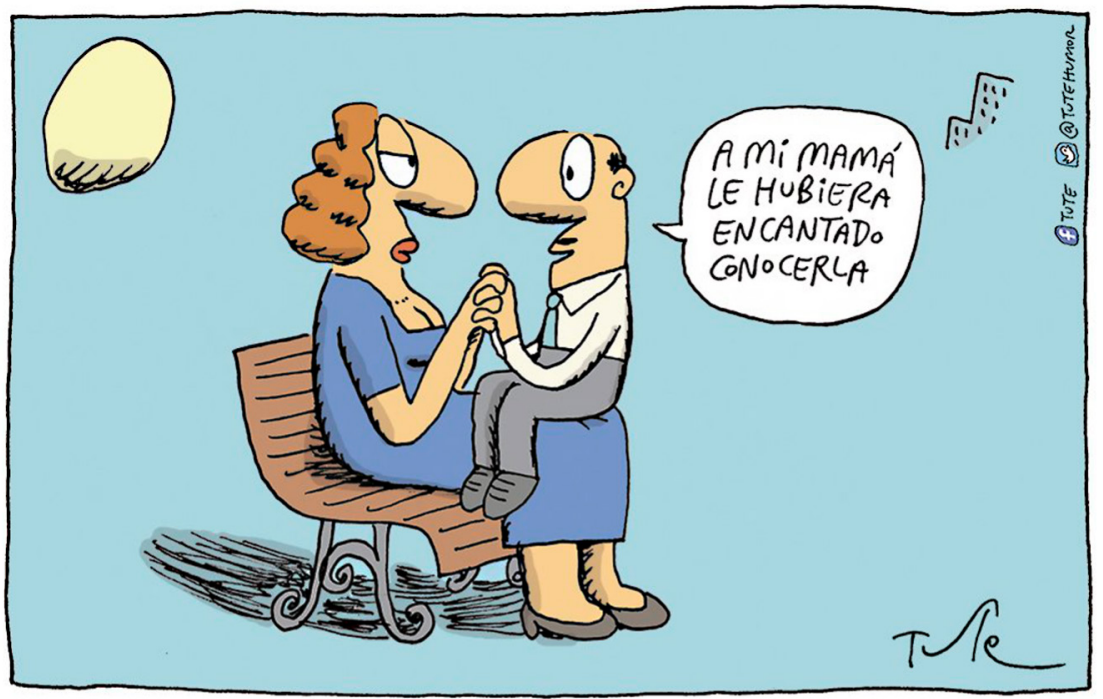

Figura 3.

El libro de Tute en la APA subraya cómo el discurso psicoanalítico puede ser empujado mucho más allá de la clínica y conectarse con el ambiente cultural de Buenos Aires. La discusión entre distinguidos psicoanalistas de una obra de gran popularidad entre lectores no especializados muestra cómo este discurso puede ser mediatizado y representado fuera del encuentro clínico. Tute mismo admitió que no lee teoría psicoanalítica, pero que su propia experiencia como analizante le ha permitido apropiarse del psicoanálisis como marco interpretativo a través de su representación artística. Que dos analistas destacados 
participen en la discusión sobre el libro utilizando técnicas y discursos psicoanalíticos legitima aún más el uso del psicoanálisis fuera de la clínica. Cuando Tute declara que ve el análisis más como una forma de arte que como una "ciencia exacta", amplifica aún más esta separación del psicoanálisis de la clínica. Y al conceder que hay algún tipo de cura durante la interacción entre analizante y analista, reconoce el valor de esa práctica.

La mediatización vincula procesos de comunicación con procesos de mercantilización (Agha, 2011). Por ejemplo, en el encuentro analítico, el discurso está atravesado por una transacción económica: habrá un pago involucrado al final de la sesión, mediante un contrato altamente ritualizado y privado entre psicoanalista y analizante. Pero hay otras prácticas mediatizadas (comunicativo-mercantilizadas) más allá de la interacción cara a cara de la clínica. Como se mencionó más arriba, la publicidad, los periódicos o el tarot son prácticas no solo fuera de la clínica, sino que implican una transacción económica. La presentación de Tute le proporcionó una oportunidad de vender libros, los cuales firmó gentilmente al finalizar la charla. A través de este proceso de mediatización, los discursos psicoanalíticos se transforman en un producto de consumo masivo: un libro que se vende por \$20 dólares.

A medida que proliferan las prácticas mediatizadas, emergen preocupaciones acerca de su autenticidad y legitimidad. Que Tute sea considerado por representantes de la APA como "el representante del psicoanálisis en todos nosotros", a pesar de que él afirmó claramente no ser un experto en psicoanálisis y no estar interesado en convertirse en uno, sugiere una ambigüedad respecto de quién está autorizado a utilizar el psicoanálisis como marco interpretativo. Cuando entrevisté a Tute en su estudio en San Telmo, admitió que no le gustan las interpretaciones no expertas que hacen los porteños. Sintió que eran intrusivas y, muchas veces, "cualquier cosa". En su trabajo, dijo, emplea creativamente una teoría que está abierta a cualquiera. Él no está haciendo psicoanálisis, sino usando sus ideas y conceptos principales "para crear algo nuevo". Al reciclar los discursos psicoanalíticos, Tute los descentra del ámbito de la clínica, dando lugar a una variedad de resultados.

Humor al diván no es el primer libro de Tute sobre el psicoanálisis. En 2012 publicó Tuterapia (Tute, 2012), juego de palabras entre el nombre Tute y la frase "tu terapia". Tuterapia tiene un prólogo del escritor y psicoanalista Gabriel Rolón, de quien se podría decir que es, en la actualidad, el más famoso difusor de las 
ideas psicoanalíticas para el público no especializado. En el prólogo, Rolón afirma que el psicoanálisis busca "una verdad que se esconde tras la barrera de la represión". ${ }^{11}$ Los libros de Tute incluyen muchas representaciones de esta idea de "búsqueda de la verdad". Por ejemplo, un dibujo muestra a un hombre recostado en el diván hablando y a sus palabras construyendo un laberinto cavernoso, que su analista investiga con una lámpara. Tras un buen rato de búsqueda, la cabeza del analista asoma por uno de los huecos de la caverna y le pide al analizante continuar la próxima vez.

Tute no es el único en usar ideas psicoanalíticas a través de una cadena mediatizada. Quino, el humorista gráfico más reconocido de la Argentina (el creador de Mafalda, una historieta icónica traducida a más de veinte idiomas ${ }^{12}$ ), también utiliza la figura de la relación entre analista y analizante en su trabajo. Otro artista gráfico, Rep (Miguel Repiso), desarrolló el personaje de Gaspar, el Rebolú (un juego entre la palabra "revolucionario" y "re-boludo" o "muy tonto"), un angustiado padre de izquierda a quien Rep retrata casi siempre recostado en el diván hablando con su psicoanalista. Las mujeres retratadas por Maitena Burundarena (Maitena) en libros de gran popularidad en Argentina e internacionalmente se refieren en ocasiones a sus sesiones de terapia. Rudy (Marcelo Daniel Rudaeff, quien también es psicoanalista), crea historietas psicoanalíticas que frecuentemente hablan de economía, actualidad y política. Fernando Sendra, colaborador del periódico Clarín desde hace mucho tiempo, también se centra en la experiencia analítica para dibujar a algunos de sus personajes. A través del proceso de mediatización, estos humoristas gráficos, entre los más reconocidos e influyentes de su campo, transforman los discursos psicoanalíticos en formas mercantilizadas que crean particulares divisiones de trabajo (dibujante, editores, instituciones) y contribuyen a la circulación de los discursos psicoanalíticos.

11 Rolón, un analista que se autoproclama como lacaniano, utiliza la palabra barrera como una metáfora del famoso sujeto barrado de Lacan, el conflicto interno que emerge en la infancia cuando comienza el proceso de individuación.

12 En el libro Mafalda, historia social y política, la historiadora Isabella Cosse (2013, p. 17) sitúa a Mafalda en la misma categoría que El Che Guevara (ícono revolucionario), Gardel (la mayor estrella del tango en Argentina) y Evita (ícono político y popular), diciendo que "sin dudas Mafalda es un ícono argentino. Es una figura y una tira cómica con significado social, político y subjetivo que no puede ser ignorada cuando se trata de entender a los argentinos". 


\section{Psicoanálisis en televisión}

La escucha sigue jugando un papel central en este proceso de circulación, facilitando la propagación de los discursos psicoanalíticos a través de las fuerzas del mercado de Argentina. Una buena ilustración de esto puede verse en las representaciones del psicoanálisis y de la escucha psicoanalítica en la televisión.

El psicoanalista Gabriel Rolón se ha convertido tal vez en el más famoso interlocutor entre el psicoanálisis y el público no especializado en Argentina. Además de trabajar como psicólogo clínico en su consulta privada, ha escrito nueve libros sobre psicoanálisis. Libres de jerga, están escritos en una prosa accesible a lectoras/es con poco o ningún entrenamiento o exposición al psicoanálisis. Todos sus libros se han convertido en éxitos de ventas. Pero la fama de Rolón ha trascendido libros y presentaciones de libros, haciendo circular ideas psicoanalíticas entre el público de los medios masivos de comunicación. Ha aparecido en numerosos programas de televisión (Va x vos, Siempre listos, Todos al diván, ¿A vos quién te ama? y Animales sueltos, para mencionar sólo algunos) y ha producido y conducido tres programas de radio propios.

En su programa Noches de diván, la gente llama por teléfono a la radio para contar un problema o una situación particular en público. Rolón amablemente "analiza" la situación en términos psicoanalíticos, sugiere algunas conclusiones y ofrece consejo a la persona que llamó. En los programas de televisión, proporciona "análisis" en muchos formatos, desde "analizar" de manera informal a todo el grupo de personas que trabajan como presentadoras de un programa nocturno, hasta un acto más formal de análisis individual, donde alguien famoso se acuesta en el diván mientras Rolón representa una sesión clínica "convencional". A veces es invitado a un programa de deportes para discutir las fobias de atletas famosas/os. En todas estas apariciones, la naturaleza seductora de los métodos y discursos psicoanalíticos con que Rolón "analiza" a la gente en público le da a la audiencia la sensación de que ha sido admitida en uno de los espacios más privados y ritualizados: la sesión de terapia. El éxito de estas representaciones terapéuticas es evidenciado en la popularidad de varias formas mediatizadas de psicoanálisis: programas de radio y televisión, libros populares, café-concert e incluso teatro comercial.

¿Cómo construye Rolón su autoridad? La expertise es intensamente referencial. Las/os actores expertos utilizan recursos lingüísticos y metalingüísticos 
tales como argot y acrónimos para estructurar sus interacciones. La expertise requiere por lo tanto de una maestría verbal que incluye la habilidad de usar el lenguaje para señalar y ejemplificar niveles de conocimiento (Carr, 2010; Silverstein, 2003). Rolón exhibe su saber y su habilidad en sus charlas recordando a Freud y a Lacan, describiendo diagnósticos de salud mental y su etiología, y representando, de alguna manera, el papel de un doctor. También incluye a filósofos como Platón, Descartes o Nietzsche, mediante el discurso indirecto: "Nietzsche tiene una frase que describe bien la personalidad del psicótico...".

Pero no sólo el lenguaje construye tropos de expertise. Las y los expertos también deben hacer uso de su dominio de la escucha.

El 28 de abril de 2017, durante el programa Cortá por Lozano ${ }^{13}$-en referencia a la expresión cortar por lo sano, que significa acabar de modo radical con una situación molesta-, Gabriel Rolón apareció para promover el estreno de la película Los padecientes, basado en uno de sus libros publicado en 2010. Una voz en off lo introdujo: "Rolón no es solo psicoanalista y autor de betsellers, también es actor, músico, maestro, conductor de radio, y una cara conocida de la televisión... Sus libros lo convirtieron en el analista más famoso del país y un escritor de éxito... Gabriel Rolón es la excepción al proverbio que dice que el que mucho abarca poco aprieta porque en cada una de sus actividades se entrega con una pasión incomparable. Pero sus múltiples roles tienen un núcleo en común que es lo que mejor hace: saber escuchar".

Inmediatamente luego, la anfitriona Verónica Lozano empezó a conversar con Rolón:

\section{VL: Verónica Lozano}

GR: Gabriel Rolón

VL: Muy bien, saber escuchar

GR: Cosa que no me va a servir de nada en este momento, porque es el momento para hablar, ¿no? Viste que yo, a veces, yo agradezco, así la posibilidad de poder dar notas, tener conversaciones. Porque, como decía el informe, los analistas

13 Cortá por Lozano es un programa argentino de televisión en Telefé, uno de los principales canales televisivos de ese país. El programa cubre una variedad de temas, es un magazine que incluye noticias, entrevistas y humor. Se estrenó el 23 de enero de 2017, y se emite todos los días a las 5 de la tarde. Es conducido por Verónica Lozano. Lozano es licenciada en Psicología, entonces invita a personas famosas a "analizarse": ellas se sientan en un diván y Lozano les hace preguntas. 
estamos un poco, no digo condenados porque es una elección, pero estamos destinados a escuchar. A escuchar siempre lo que le pasa al otro, lo que le duele al otro, y entonces, algunos momentos para conversar, para poder hablar de lo que nos pasa a nosotros, siempre lo agradezco así que gracias por la invitación.

La escucha estructura la interacción de este encuentro desde el principio: Rolón es alguien que sabe escuchar, un oyente experto. Mediante una serie de observaciones (subrayadas), Rolón expresa su alivio porque no tendrá que escuchar, sino que va a hablar sobre las cosas que le suceden a él, y a las/os analistas en general. Pero sus deseos se verán rápidamente frustrados luego del comienzo de la entrevista.

Siguiendo el emotivo relato de una experiencia que Rolón tuvo con su padre muerto, Lozano (quien también es psicóloga), aprovecha una breve pausa para asignarle a Rolón la realización de un nuevo acto de escucha:

1 VL: Qué lindo [lo que nos acaba de contar]. Ahora te voy a dar trabajo porque tenemos para analizar unos lapsus, actos fallidos ponele.

2 GR: Ponele.

$3 \mathrm{VL}$ : Vamos con el primero a ver qué podemos decir de esto...

Hay un corte y aparece un video de un cura oficiando una ceremonia en la que dice:

\section{Por dios, por la plat/por la patria}

5 VL: Por dios, por la plat/ por la patria

6 GR: iQué bárbaro!, ¿no? Bueno, primero vamos a hacer una aclaración, usted es colega, Vero, así que lo sabe: Freud dijo una vez que a veces un cigarro es nada más un cigarro, ¿sí? O sea: a veces una equivocación es solo una equivocación. $7 \mathrm{VL}$ : En este caso no lo parece (risa estentórea). Me permito [interpretar eso]. 8 GR: Me encanta porque lo vamos analizando a dúo, si acá somos dos terapeutas, dos psicólogos. Entonces, quiero decir, el acto fallido o el lapsus tiene importancia cuando es dicho frente al analista, es decir, dicho frente a alguien para que lo escuche.

$9 \mathrm{VL}:$ Ok.

10 GR: ¿Sí? Bueno, tiendo a pensar que es posible que en muchos de estos casos se trate de un acto fallido o de un lapsus, porque el pueblo es un otro que está ahí para escuchar. 
11 VL: Claro, es una gran oreja, escucha.

12 GR: Es una gran oreja para escuchar, entonces. No en todos los casos, pero muchas veces puede ser, y por eso hay que saber escuchar bien cuando elegimos, cuando votamos, y también a veces tener la generosidad de entender que viene alguien de hacer diez campañas y/

13 VL: Puede equivocarse

14 GR: por ahí estuvo hablando dos minutos antes...

$15 \mathrm{VL}$ : o contando mucha plata, tal vez [risa estentórea]

16 GR: ... o pensando a quién le iba a dar tanta plata, ¿esta plata es para quién?

17 VL: también, también

18 GR: y te quedó el significante de la palabra dando vueltas y cometiste esto que te condena públicamente... [risas].

19 VL: Le mandamos un besito y tenemos otro. Este es diferente, vamos a analizarlo juntos.

Rolón demuestra ser un diestro comunicador, es cuidadoso de no caer en interpretaciones maliciosas. Para ello, comienza por incluir a Lozano en su interpretación: “vos sos colega, Vero...", expandiendo así el marco interaccional y posicionándolos a ambos en la categoría de expertos. Continúa citando la idea de Freud de que a veces los discursos no tienen dobles sentidos. Lozano, autorizada para interpretar, afirma que este no es un caso de confusión (línea 7). Rolón legitima esta interpretación (línea 8) subrayando una vez más el hecho de que ella también es psicóloga. Sin embargo, en ese momento cambia el registro: pasando a un lenguaje más formal, Rolón explica que los lapsus o deslices freudianos sólo tienen sentido en el contexto de un oyente. Para no contradecir directamente a Lozano, Rolón explica que la escucha también puede ser una experiencia colectiva que puede legitimar ciertas interpretaciones, y proporciona diferentes escenarios que pueden explicar la confusión del cura. Concluye expresando simpatía acerca de cómo un error puede desacreditar a un sujeto. Estas estrategias discursivas le permiten a Rolón mantener el control sobre el intercambio sin tener que contradecir a Lozano. Él pone en acto su pericia pero también la incluye a Lozano, incluso cuando disiente con ella.

Además de una virtuosa función psicoanalítica, este intercambio propone tres ideas sobre la escucha, expresadas en las observaciones de Rolón. La primera, que los lapsus o deslices freudianos sólo suceden cuando hay alguien 
para interpretarlos como tales (línea 8). La segunda, la conceptualización figurativa de que el pueblo es "una gran oreja", permitiendo que el interlocutor de una interacción de uno a uno sea reemplazado por la sociedad en su conjunto (líneas 10-11). Y la tercera, dado que cualquiera puede escuchar, es responsabilidad del sujeto "aprender" a escuchar antes de tomar cualquier decisión importante: la sobreinterpretación es arriesgada (línea 12). Las/os oyentes tienen que ser generosos cuando escuchan y no sacar conclusiones apresuradas. Rolón plantea una ética de la escucha: es la responsabilidad del oyente de evitar confusiones, y especialmente evitar meter a sujetos en discursos arbitrarios. Lozano intenta en dos ocasiones (líneas 7 y 15) forzar una interpretación particular: el cura está pensando en el dinero y probablemente no en dios. Pero Rolón se mantiene fuera de la interpretación y sigue proponiendo explicaciones alternativas. Hay una superposición entre Rolón y Lozano (líneas 12-13-1415) hasta que Lozano se rinde y admite que este puede ser un simple error, y concluye su intervención mandándole besos al cura (línea 19).

La escucha psicoanalítica en tanto género circula y es representada en forma mediada. Cuando Rolón explica en su rol de experto que "el pueblo" es una gran oreja, democratiza la escucha, de manera que cualquiera está autorizada/o a escuchar y puede hacer interpretaciones. Si cualquiera puede escuchar psicoanalíticamente, la fórmula cuando dices $X$ yo escucho $Y$ ("lo que en realidad quieres decir es...") emerge como un índice de cómo la gente está escuchando y, lejos de ser una imposición, se convierte en una forma de sociabilidad en la cual una persona puede ser interpretada por otra. Este intercambio televisado sirve como herramienta pedagógica que contribuye a la más amplia presencia del género de la escucha psicoanalítica.

A su vez, los programas televisivos, la escritura y otros trabajos de Rolón son creados y vendidos en un mercado capaz de expandir la circulación de un género de escucha. Estructurado alrededor de ideologías modernas específicas, con raíces teóricas identificables, la gran popularidad de este género se retroalimenta con su mercantilización. Como diría Marcel Mauss, no hay regalo que sea gratuito. Rolón aparece en un programa para promover un filme basado en su novela, ambos productos mercantilizados engendrados por discursos sobre el psicoanálisis. El tiempo publicitario y de aire que Lozano le cedió al film es ofrecido a cambio de la disposición de Rolón para realizar el trabajo de escuchar psicoanalíticamente. 
La circulación en televisión de la escucha psicoanalítica como género puede verse también en la entrevista a Rolón en el programa Animales sueltos, conducido por Alejandro Fantino, el 9 de junio de 2018. Durante la entrevista, Fantino manifiesta su emoción y entusiasmo por entrevistar a Rolón, contándole que siempre lleva consigo un anotador en el que registra cada vez que presencia algo interesante, con la esperanza de preguntarle a Rolón al respecto.

Fantino le cuenta a Rolón que una vez le preguntó a uno de los tatuadores más famosos de Argentina cuál es el tatuaje más común que pide la gente. El tatuador le propuso a Fantino que adivinara, dándole una pista: "es una palabra que muchas mujeres piden". Fantino propuso las palabras "paz" y "amor", pero el artista dijo: "no, tatuamos aproximadamente cinco o seis veces al día la palabra 'soltar". La entrevista continúa con el siguiente intercambio:

\section{AF: Alejandro Fantino \\ GR: Gabriel Rolón}

1 AF: ... empecemos con esa palabra, la más tatuada, soltar, ¿qué es soltar? ¿Cómo entiende la psicología, o cómo entendés vos lo que es soltar?

2 GR: Mirá, creo que es interesante que elijan esa palabra porque básicamente tenemos la idea de que no podemos ser felices porque tenemos mucho peso. ¿Sí? Así que cuando te dicen, bueno, "tenés que soltar", ¿soltar qué? Soltar los mandatos, soltar la historia, soltar una historia de amor específicamente, digamos que no la soltaste y te dicen, "soltá, volvé a salir, conocé a alguien, soltá tu pasado, para decir..."

3 AF: Pero, ¿se supone que debés andar por el mundo con poco peso?

4 GR: Mirá, creo que es imposible ir por el mundo con poco peso, lo que hay que intentar es llevar sólo el peso imprescindible o inevitable.

5 AF: ¿A qué le llaman peso los psicólogos? Porque yo te puedo decir lo que peso significa en la física, pero no sé lo que peso significa en psicología, ¿a qué le llaman peso?

6 GR: Mirá, más que nada es una metáfora para, en mi opinión, esas cosas que... no sé si para la psicología, yo trato de traducir lo que la gente me dice...

7 AF: Sí, exactamente.

8 GR: ... cuando [alguien] me dice "cargo mucho peso". Mmmh, imaginate esto, ¿sí? Es como si todos naciéramos con una mochila, una mochila en la que, poco a poco, a medida que vamos viviendo, muchas personas ponen cosas, algunas 
cosas son buenas y otras son malas, nos ponen frases, palabras, alguien pone una piedra que dice "nunca serás feliz", otro pone algo.../

9 AF: ¿Te pueden poner eso? ¿Hay gente a la que le ponen eso en su mochila? ¿Nunca vas a ser feliz"?

10 GR: Pero claro, "no servís para nada", hay formas de meter [la piedra]. Mirá, cuando una madre o un padre le pide a un chico que trabaje en algo, y a los dos minutos viene [el padre] y le dice "dejá, dejá, dejá. Dejá, lo voy a hacer por vos", ¿qué le está diciendo? "No servís para nada". "Dejá que lo haga yo porque sos un inútil, no podés hacerlo".

11 AF: En ese pequeño acto le estás poniendo una piedra que tiene eso [inscrito] en la mochila del chico.

Tal vez lo más sorprendente en este intercambio es la naturaleza polisémica de las palabras que utilizan Fantino y Rolón. Están manteniendo una conversación sobre el significado de las palabras; las personas de profesiones diferentes asignan significados distintos a las palabras dependiendo del contexto. Fantino comienza preguntando qué podría significar que las mujeres se tatúen la palabra "soltar". Sugiere que hay algún significado oculto no disponible para él. Primero pregunta qué significado le asignan las psicólogas a este término, pero rápidamente cambia la pregunta para interrogar a Rolón acerca de cómo lo interpretaría él. Rolón explica que "soltar" está relacionado con la idea de cargar peso a medida que uno va a cumulando experiencias a lo largo de la vida. Esto da pie a Fantino para preguntar acerca de la palabra peso. En el fragmento 5, asegura saber lo que expresa el significado para la física, pero le gustaría saber qué puede significar "peso" para la psicología. Rolón comienza a responder, pero inmediatamente se da cuenta (en un acto de autorreparación) de que no va a hablar sobre psicología sino de lo que él interpreta en las palabras de sus pacientes (fragmento 6) ("lo que en realidad quieren decir es..."). Rolón explica que la palabra "peso" es utilizada como una metáfora. Para ilustrar esta idea, presenta la alegoría de alguien que carga una mochila en la que la gente deposita palabras y frases y que empieza a sentirse pesada. Algunas personas introducen palabras que se sienten como si fuesen piedras con la leyenda "nunca serás feliz" (fragmento 8). Fantino se sorprende ante la idea de que alguien pueda poner esas palabras en la mochila imaginaria, y Rolón, ahora investido con su rol de analista, explica 
que el "significado real" de las palabras de los padres cuando le dicen a un niño que deje de hacer algo que antes le pidieron que hiciera, es un metamensaje cruel: "no servís para nada".

La idea de que todo tiene un significado más allá de la pura denotación se repite una y otra vez. Como le explica Rolón a Fantino (fragmento 6), lo que él hace es traducir las palabras que la gente le dice. Esta traducción depende de escuchar "eso que no ha sido dicho" trayendo a la superficie las prácticas inconscientes, los verdaderos motivos que impulsan el propio comportamiento. También hemos visto a Rolón expresar la idea de que aquello que las palabras comunican depende de cómo lo reciben los oyentes; otra dimensión crucial del género de escucha psicoanalítica.

En esta conversación entre Rolón y Fantino, hay varios elementos clave del género de la escucha psicoanalítica mediatizados para una audiencia televisiva. El contexto de esta actuación y la remuneración que reciben ambos, Rolón y Fantino, subraya cuan natural y concienzudamente el género de escucha psicoanalítica puede ser empaquetado y distribuido a través de los medios para el consumo público. No es esencial que los televidentes comprendan de manera consciente el modelo de escucha que describe Rolón. Pero Rolón y, de alguna manera, Fantino, son parte de un ecosistema mediático más grande en el que el discurso psicoanalítico es parte de la vida cotidiana y la escucha es clave para entender sus cosmovisiones.

Como muestro en la siguiente sección, a veces las palabras están unidas a historias, mitos y cosmovisiones complejas. En Buenos Aires, el psicoanálisis se ha convertido en una práctica cultural que representa el mundo a través de ideologías particulares del yo, pero también de género, en las cuales la figura de la madre ocupa un rol importante.

\section{Comerciales}

Los discursos mediatizados sobre el psicoanálisis son comunicables en parte porque los consumidores fueron formados por la circulación ubicua de estos discursos y continúan a su vez diseminándolos y reciclándolos. El lenguaje usado por los medios está impregnado pues de significado semiótico capaz de comunicar muchas ideologías y creencias. $Y$ es tan poderoso y reconocible que también lo utilizan los publicistas argentinos, aunque de una manera peculiar. 
En su célebre libro Wisdom sits in places, Keith Basso (1996) analiza cómo los Apaches de Cibecue asignan significado a los lugares relevantes para su vida social. La relación entre el paisaje y la lengua es tan estrecha, que la sola invocación del nombre de un lugar sirve para educar y transmitir la cultura de los antepasados cibecue. Más que ser descriptivos, los nombres están acompañados por una historia que generalmente encierra una lección moral. En el capítulo titulado "Speaking with names" ("hablando en nombres"), Basso describe el caso de Louise, preocupada por la conducta temeraria de su hermano, quien meses atrás pisó una piel de serpiente y no completó el ritual necesario para protegerse de este percance, y ahora está enfermo. Louise les cuenta esto a sus tres amigos, Lola, Emily y Robert, y es interrumpida por Lola, quien dice: "Esto sucedió en la Línea de Rocas Blancas Que Se Extiende Arriba y Afuera, jen este preciso lugar!", ${ }^{14}$ tras lo cual, misteriosamente, nadie responde por 30 o 40 segundos. En otro momento Emily dice: "Sí. Sucedió en Blancura Esparcida Descendiendo hacia el Agua, jen este preciso lugar!", ${ }_{15} \mathrm{y}$ se hace otra larga pausa, hasta que Lola menciona el nombre de otro lugar. Louise sonríe y Robert declara: "La amabilidad y el bien se harán presentes" ${ }^{16}$ Luego de este intercambio Louise, visiblemente de mejor ánimo, le dice a su perro que su hermano simplemente ha actuado como un tonto.

Para Basso, como para cualquiera que no esté familiarizado con esta forma de comunicación, el intercambio era incoherente. A través de su trabajo etnográfico, sin embargo, llegó más tarde a entender que hablar con nombres implica un sofisticado proceso metacomunicativo, en el cual cada nombre de lugar está conectado con una historia específica. Las largas pausas entre cada intercambio son necesarias para visualizar el lugar y así recordar la historia conectada con ese lugar. Los nombres de lugares referidos por los amigos de Louise expresaban en realidad la historia de una persona que se comportó mal, sufrió las consecuencias de su comportamiento y, sin embargo, tuvo un final feliz. Las "imágenes" suscitadas por los nombres tuvieron el efecto perlocucionario de calmar la angustia de Louise.

14 "It happened at Line Of White Rocks Extend Up and Out, at this very place!".

15 "Yes. It happened at Whiteness Spread Out Descending to Water, at this very place!".

16 "Pleasantness and goodness will be forthcoming". 
Los actos perlocucionarios son actos de habla que "extienden" la ilocución de un enunciado, teniendo un impacto o consecuencia directa en el oyente (por ejemplo, persuadiendo, inspirando, prometiendo). El ejemplo Cibecue muestra cómo la metacomunicación juega un rol en las interacciones de la vida cotidiana: las palabras más ordinarias pueden transportar significados que van más allá de su capacidad denotativa. Los nombres expresan una forma particular de conocimiento cultural que circula y los actores sociales se relacionan de diferentes maneras con cada nombre. La ilocución de la fórmula "cuando dices $X$ escucho $Y^{\prime \prime}$ también es un acto perlocucionario. Al aceptar esta interpelación, aparecen en el oyente las dudas, preocupaciones e incertidumbres, generando un estado mental particular. De modo similar al pueblo Cibecue, en Buenos Aires, a través de la naturaleza mediatizada de los discursos psicoanalíticos, hay ciertas palabras y nombres que están asociados a una cadena semiótica (por ejemplo, mitos o historias), que expresan un significado cultural particular propio.

En el verano de 2018, una publicidad televisiva llamó mi atención. Era un comercial de Fernet, ${ }^{17}$ un aperitivo italiano muy popular en Argentina que se suele mezclar con Coca-Cola. El comercial estaba presentando Fernet 1882, que viene ya mezclado con Coca-Coca, listo para tomar. El eslogan del nuevo envase, "extremadamente práctico", señala las ventajas de no tener que abrir y mezclar el contenido de dos botellas. El anuncio comienza con un analista sentado en una moderna oficina en la que un hombre joven que acaba de llegar empieza a recostarse sobre un diván vacío. Antes de acostarse completamente, ocurre el siguiente intercambio:

$\mathrm{P}=$ Psicoanalista

J= Julián (paciente)

1 P: ¿Cómo estás, Julián?

$2 \mathrm{~J}$ : No sé.

3 P: La culpa es de tu madre.

$4 \mathrm{~J}$ : Claro.

5 P: Nos vemos la próxima semana.

$6 \mathrm{~J}$ : Dale.

17 El comercial se puede ver en YouTube (cf. Nuevo Fernet..., 2017). 
Al mismo tiempo que dice "Dale", Julián empieza a levantarse del diván. Luego aparece un fondo negro con las palabras "extremadamente práctico", seguido por la apertura de una lata del nuevo Fernet. Hay un corte a otro fondo negro con el nombre 1882 Sabor Fernet \& Cola, seguido por las palabras "listo para tomar".

El intercambio entre Julián y el analista ocupa apenas cinco de los quince segundos que dura el comercial. Pero en este brevísimo período de tiempo tiene lugar un despliegue de ideologías, estereotipos y discursos. En la publicidad de Fernet podemos escuchar la palabra que comunica un significado muy idiosincrático: "madre", la progenitora femenina, que expresa en Buenos Aires dos historias omnipresentes en múltiples discursos y formas: la historia de la madre como la fuente de anomalías psicológicas y la historia de Edipo.

La primera historia, como muestra la historieta de Sendra al comienzo de este capítulo, está conectada con la ideología de que la relación que los sujetos desarrollan con sus madres determina la mayoría de los aspectos de sus vidas, asociada generalmente con resultados negativos. Académicas feministas han argumentado que esta creencia es tan predominante que es casi axiomática: ambos padres son responsables de nuestro nacimiento, pero nuestras madres son las que aparecen como esenciales. El autoescrutinio en busca de signos que indiquen "normalidad", "anormalidad", "patología", los plantea como resultado directo de la relación con nuestras madres (ver Lawler, 2000). La madre se ha convertido, como dijeron Valerie Walkerdine y Helen Lucey (1989, p. 15), en "la garante del orden liberal [democrático]" ${ }^{18}$ Es tarea de la madre producir el yo bueno, saludable y bien administrado, que a su turno defenderá la democracia.

En el anuncio de Fernet, la palabra "madre" replica esta ideología. Cualquiera sea el problema que experimente Julián, es culpa de su madre. Cuando el analista le pregunta cómo está, él no expresa ni una falta de compostura ni malos sentimientos, su respuesta es neutral: "No sé” (línea 2). La reacción del analista a la declaración de Julián es implicar a su madre. Julián legitima la interpretación del analista respondiendo rápidamente "claro" (línea 4), subrayando la naturaleza autoevidente de este discurso. Si aplicamos el eslogan del comercial, "extremadamente práctico", esto es, que no tienes que hacer nada más que servir el contenido de la lata, a la interacción entre Julián y el analista, encontramos

18 Original: "the guarantor of the liberal [democratic] order". 
el siguiente mensaje: "tan práctico como saber instintivamente que las madres son responsables de todos nuestros problemas". Y hay además un subtexto, a modo de burla del encuentro analítico, que sugiere que "vas a terapia por años sólo para darte cuenta de que todo se reduce a tu relación con tu madre".

La asociación negativa "madre equivale a problemas" no es exclusiva de la Argentina. La maternidad ha sido largamente conceptualizada mediante discursos de extrema benevolencia y sacrificio, o como patológica y dañina (ver Chodorow, 1978). La ideología hegemónica que distingue a algunas personas como "saludables", "buenas madres" o "buenos niños", por un lado, de los patologizados, por el otro, predomina en muchas culturas. Lo excepcional en Buenos Aires es el vínculo entre esta asociación negativa y el psicoanálisis.

En la publicidad de Fernet vemos cómo el psicoanálisis estructura la idea de maternidad, y cómo estos discursos son reciclados por los medios conforme estos difunden ideologías y crean identidades sociales. Durante mi investigación en Buenos Aires, perdí la cuenta de cuántas veces amigos y conocidos expresaron una conexión directa entre sus problemas y su relación con sus madres, mientras hablaban mucho menos sobre sus padres. La palabra "madre" sigue una cadena semiótica singular a través de una historia que conecta madres con problemas, y esta historia está muy presente en la teoría psicoanalítica.

La exitosa comunicabilidad de este discurso radica en lo internalizada que está esta historia en Argentina. Al igual que en los lugares-nombres Cibecue, la palabra "madre" en Argentina dispara una historia particular, aunque sea negativa. Efectivamente, esta idea se ha vuelto tan extendida en Buenos Aires que diversas compañías pueden capitalizarla y utilizarla para vender productos de consumo masivo.

La segunda historia vinculada a la palabra madre es el mito del Complejo de Edipo: las complejas emociones que despierta en un niño el deseo inconsciente por el progenitor del sexo opuesto. ${ }^{19}$ Esta historia está ilustrada con claridad en

19 El complejo de Edipo positivo se refiere al deseo sexual inconsciente del niño por el progenitor del sexo opuesto y el odio hacia el progenitor del mismo sexo. El complejo de Edipo negativo se refiere al deseo sexual inconsciente del niño por el progenitor del mismo sexo y el odio hacia el progenitor del sexo opuesto. Freud consideraba que la identificación del niño con el progenitor del mismo sexo es el resultado exitoso del complejo y que el resultado no exitoso del complejo podría conducir a la neurosis, la pedofilia y la homosexualidad. 
un comercial argentino de mayonesa Hellmann's, ${ }^{20}$ emitido por primera vez en 2004 para celebrar el Día de la Madre. El comercial -que muchos podrían considerar inapropiado- dura cincuenta segundos, basada en la canción de amor "Algo contigo", en la voz del famoso cantante argentino Vicentico. La letra de la canción habla de un hombre desesperadamente enamorado de una mujer:

¿Hace falta que te diga que me muero por tener algo contigo?

¿Es que no te has dado cuenta de lo mucho que me cuesta ser tu amigo?

Ya no puedo acercarme a tu boca, sin deseártela de una manera loca.

Necesito controlar tu vida, ver quién te besa y quién te abriga.

El comercial presenta las interacciones de cinco niños, de entre aproximadamente dos y once años de edad, con sus respectivas madres. Mientras las madres le agregan mayonesa Hellmann's a diferentes platos, los chicos las miran de una manera que puede ser interpretada como lujuriosa. El primer chico le dice a su madre: "Mami, sos el amor de mi vida"; el segundo se queda mirándola anonadado; el tercero le dice: "sos una mujer increíble"; el cuarto le agarra el brazo diciéndole: “¿te dije alguna vez que te quiero?”, a lo que ella responde con una mirada tierna y sorprendida. El último niño, prácticamente un bebé, le dice a su madre (obviamente mediante un truco visual) "me encantás". La madre atónita le pide que repita lo que acaba de decir, y el niño responde con un balbuceo normal a su edad. El comercial termina con el eslogan "Hellmann's mayonesa es dar lo mejor".

El efecto combinado de la canción, las miradas lascivas de los niños y las declaraciones de amor da la impresión de que los chicos están de hecho enamorados de sus madres. Algunos de los comentarios en la página de YouTube sobre el comercial corroboran esta interpretación: "Complejo de Edipo XD", "Incesto Emocional", "Ayy el Edipo", “¿El Complejo de Edipo en un comercial con connotación sexual? ¿O yo ya estoy muy pervertido?:S”.

El Complejo de Edipo es una de las ideas de mayor circulación engendradas por el psicoanálisis. Es un concepto multifacético que Freud desarrolló a lo largo de su carrera. Le tomó más de veinte años después de su primera

20 El comercial se puede ver en YouTube (cf. Mayonesa Hellmanns, 2008). 
discusión del mismo en La interpretación de los sueños reconsiderar su creencia de que el complejo de Edipo era igualmente válido para niñas y niños (Leonard, 2013). Es bien sabido que Freud rechazó los esfuerzos de Carl Jung (1915) de proporcionar una narrativa mítica comparable para las niñas en lo que llamó el "Complejo de Electra". En su lucha por comprender la sexualidad femenina, Freud también discutió la idea de una etapa pre-Edípica. Sin embargo, pese a su reconocimiento del deseo femenino, Freud (1953, p. 212) siguió declarando su incapacidad para comprender la sexualidad femenina, afirmando notablemente que "la vida sexual de las mujeres adultas es un 'continente oscuro' para la psicología". ${ }^{21}$

El Complejo de Edipo es un gran ejemplo de cómo la comunicabilidad difunde tropos ideológicos, reciclados a veces incluso sin relación alguna con la historia original. En Buenos Aires, en interacciones informales, la mención del Complejo de Edipo señala una variedad de situaciones sociales: puede ser una broma que describe la relación estrecha que un varón porteño tiene con su madre; puede tomar la forma de una madre que se queja de que su hijo chiquito no quiere ir al jardín y explica que "todavía está con el Edipo"; puede servir para justificar la atracción sexual de un hombre joven por mujeres mayores que él, entre muchos otros usos potenciales. En la publicidad de Hellmann's podemos ver la amalgama de un producto mercantilizado, la mayonesa, con las cadenas semióticas que lo conectan con Freud. Pero en la apelación al Complejo por parte de sujetos legos vemos la internalización de historias particulares unidas al concepto de madre.

Los dos comerciales presentan historias vinculadas a la palabra "madre" que emergen de teorías psicoanalíticas que interpelan a los sujetos como ocupando roles sociales bien concretos. Una está unida a una fuerte ideología que asocia la maternidad con la identidad. La otra, con un supuesto pasaje que todos los niños varones atraviesan. Hay una posible conexión entre ambas: la subjetividad masculina como teniendo una relación (o un apego) poco saludable con su madre. La fuerza perlocutiva de convocar la maternidad produce el mismo efecto que la forma "lo que en realidad quieres decir es...", en la que, si bien la denotación es clara, los conceptos asociados a ella son idiosincráticos

21 “[...] the sexual life of adult women is a 'dark continent' for psychology" (Freud, 1953, p. 212). 
y difieren significativamente del referente. Todos hablamos en nombres, de alguna manera; en Argentina el concepto de madre despierta historias y conceptos conectados con el psicoanálisis. Y en ese proceso la escucha psicoanalítica resulta clave.

\section{Conclusión}

El éxito de la circulación de los discursos psicoanalíticos se debe a su capacidad para proyectar ideologías como si fueran naturales y del sentido común. La publicidad, la televisión, la radio, los libros y otros medios son vehículos poderosos para la difusión y mediatización de elementos clave del discurso psicoanalítico fuera del espacio de la clínica en Buenos Aires, basadas en su comunicabilidad. En el caso extremo, la forma comunicativa es una única sílaba: el prefijo psi-. En otros casos, como el de Rolón, historias más largas son recicladas de modo fragmentario proyectando ideologías sobre el psicoanálisis. El concepto de mediatización ayuda a arrojar luz sobre el modo en que una relación social determinada creada dentro del espacio de la clínica -la relación entre analista y analizante- es replicada fuera de dicho espacio, y a rastrear las cadenas semióticas que la precedieron y la continuaron (similares a las esferas de comunicación de Bajtín). La comunicabilidad, por otra parte, es una lente crucial para entender cómo interactúan los roles de producción, difusíon y consumo de discursos psicoanalíticos, y cómo estas relaciones construyen un producto completo y lo proyectan a un público extenso.

La escucha es clave en estos procesos, mencionada de manera explícita, transformada en trabajo, o bien a través de la evocación de determinadas historias. Los abundantes ejemplos de psicoanálisis en los medios colaboran en la circulación de la ideología según la cual hay más que denotación en cada afirmación pronunciada. Las publicidades, los programas de televisión y el humor gráfico replican en algunos casos prácticas de escucha basadas en el psicoanálisis poniendo en acto ideologías de "lo que en realidad quieres decir es". En otros casos, la recepción perlocucionaria de las palabras desencadena historias que están conectadas con figuras e ideologías míticas.

Estas representaciones resaltan cómo los discursos psicoanalíticos que permean Buenos Aires y la Argentina están basados en el psicoanálisis como un 
género de escucha. Aun en su forma textual, el psicoanálisis implica un enorme componente de escucha. Cuando Gabriel Rolón y Verónica Lozano conversan sobre el comportamiento de la gente, o cuando Tute explica cómo su proceso creativo se parece al psicoanálisis, o cuando Sehinkman "analiza" las noticias de la noche, la escucha psicoanalítica está presente con mucha fuerza. Como un "hecho social" en Buenos Aires, la escucha psicoanalítica como género es reproducida en gran número de formas y lugares, y con cadenas semióticas que pueden rastrearse muy lejos hasta Freud. A pesar de que, en muchos casos, este género de escucha se ha vuelto tan aceptado y extendido que las cadenas se han vuelto borrosas.

\section{Referencias}

ADORNO, T. et al. The authoritarian personality. New York: Wiley, 1967.

AGHA, A. Meet mediatization. Language and Communication, [s. l.], v. 31, p. 163-170, 2011.

ALTHUSSER, L.; BALIBAR, E. Reading capital. New York: Pantheon Books, 1971.

BALÁN, J. Cuéntame tu vida: una biografía colectiva del psicoanálisis argentino. Buenos Aires: Planeta, 1991.

BASSO, K. Wisdom sits in places. Albuquerque: University of New Mexico Press, 1996.

BAUMAN, R.; BRIGGS, C. L. Poetics and performance as critical perspectives on language and social life. Annual Review of Anthropology, [s. l.], v. 19, p. 59-88, 1990.

BHABHA, H. Caliban speaks to Prospero: cultural identity and the crisis of representation. In: MARIANI, P. (ed.). Critical fictions: the politics of imaginative writing. Seattle: Bay Press, 1991. p. 62-65.

BRIGGS, C. L. Communicability, racial discourse, and disease. Annual Review of Anthropology, [s. l.], v. 34, n. 1, p. 269-291, 2005.

BRIGGS, C. L. Anthropology, interviewing, and communicability in contemporary society. Current Anthropology, [s. l.], v. 48, n. 4, p. 551-580, 2007.

BRIGGS, C. L.; HALLIN, D. C. Biocommunicability: the neoliberal subject and its contradictions in news coverage of health issues. Social Text, [s. l.], v. 25, n. 4, p. 43-66, 2007. 
BUTLER, J. Gender trouble: feminism and the subversion of identity. New York: Routledge, 1990.

CARR, E. S. Enactments of expertise. Annual Review of Anthropology, [s. l.], v. 39, n. 1, p. 17-32, 2010.

CHAKRABARTY, D. Provincializing Europe: postcolonial thought and historical difference. Princeton: Princeton University Press, 2000.

CHODOROW, N. The reproduction of mothering. Berkeley: University of California Press, 1978.

COSSE, I. Mafalda: historia social y política. Buenos Aires: Fondo de Cultura Económica, 2013.

DAGFAL, A. Entre París y Buenos Aires: la invención del psicólogo (1942-1966). Buenos Aires: Paidós, 2009.

EDELSON, M. Language and interpretation in psychoanalysis. New Haven: Yale University Press, 1975.

FOUCAULT, M. The birth of biopolitics: lectures at the Collège de France, 1978-1979. London: Palgrave Macmillan, 2010.

FREUD, S. The standard edition of the complete psychological works of Sigmund Freud. Ed. James Strachey et al. London: The Hogarth Press, 1953.

FREUD, S. Leonardo Da Vinci and a memory of his childhood. The standard ed. translated from the German. New York: Norton, 1964.

FREUD, S. El malestar en la cultura. Madrid. Alianza Editorial, 1970.

FROSH, S. The politics of psychoanalysis: an introduction to Freudian and Post-Freudian theory. New York: New York University Press, 1999.

FROSH, S. Psychoanalysis outside the clinic: interventions in psychosocial studies. New York: Palgrave Macmillan, 2010.

GAY, P. Freud: a life for our time. New York: Norton, 1988.

JUNG, C. G. The theory of psychoanalysis. New York: Journal of Nervous and Mental Disease Publishing Company, 1915.

KRISTEVA, J. Revolution in poetic language. New York: Columbia University Press, 1984. 
KRISTEVA, J. Tales of love. New York: Columbia University Press, 1987.

LATOUR, B. We have never been modern. Cambridge: Harvard University Press, 1993.

LATOUR, B. Science in action: how to follow scientists and engineers through society. Cambridge: Harvard University Press, 2001.

LATOUR, B. Reassembling the social: an introduction to actor-network-theory. Oxford: Oxford University Press, 2005.

LAWLER, S. Mothering the self: mothers, daughters, subjects. London: Routledge, 2000.

LEONARD, M. Freud and tragedy: Oedipus and the gender of the universal. Classical Receptions Journal, [s. l.], v. 5, n. 1, p. 63-83, 2013.

LÉZÉ, S. Convertirse en psicoanalista en Francia. Política y Sociedad, [s. l.], v. 43, n. 3, p. 73-87, 2006.

MARCUSE, H. Eros and civilization: a philosophical inquiry into Freud. Boston: Beacon Press, 1955.

MARSILLI-VARGAS, X. Listening genres: the emergence of relevance structures through the reception of sound. Journal of Pragmatics, [s. l.], n. 69, p. 42-51, 2014.

MARSILLI-VARGAS, X. The offline and online mediatization of psychoanalysis in Buenos Aires. Signs and Society, [s. l.], v. 4, n. 1, p. 135-153, 2016.

MAYONESA HELLMANNS. [S l.: s. n.], 2008. 1 video (1min). Publicado en el canal evaldez84. Disponible en: https://www.youtube.com/watch?v=hkvjkycfJoY. Acceso: 15 marzo 2021.

MITCHELL, J. Psychoanalysis and feminism. New York: Pantheon Books, 1974.

NUEVO FERNET 1882 RTD: Psicólogo. [S. l.: s. n.], 2017. 1 video (14s). Publicado en el canal Fernet 1882. Disponible en: https://www.youtube.com/watch?v=yYx7nqRkpng. Acceso: 15 marzo 2021.

OGDEN, T. H. Reverie and interpretation sensing something human. London: Karnac Books, 1999.

PERI, M. Aproximación psicoanalítica al tango. In: EL PSITIO. [S. l.]: Sociedad Interamericana de Psicología, 19 marzo 2009. Disponible en: http://www.elpsitio.com/ Noticias/NoticiaMuestra.asp?Id=2033. Acceso: 15 marzo 2021.

PERI, M. Tango: un abrazo sanador. Buenos Aires: Corregidor, 2015. 
PERI, M.; LAVALLE COBO, I. PsicoTango: danza como terapia. Buenos Aires: Corregidor, 2010.

PLOTKIN, M. Psychoanalysis as a belief system: a research program outline. História, Ciências, Saúde - Manguinhos, Rio de Janeiro, v. 4, supl. 1, 2017.

PLOTKIN, M.; VIOTTI, N. Between Freud and Umbanda. Therapeutic constellations in Buenos Aires, Argentina. In: NEHRING, D. et al. (ed.). The Routledge international handbook of global therapeutic cultures. London: Routledge, 2020. p. 247-267.

PLOTKIN, M., VISACOVSKY, S. Saber y autoridad en las intervenciones de los psicoanalistas en torno a la crisis en la Argentina. Estudios Interdisciplinarios de América Latina y El Caribe, [s. l.], v. 18, n. 1, p. 13-40, 2007.

RODRÍGUEZ, C. El ejército de ocupación. Página/12, Buenos Aires, 15 ago. 2019. Disponible en: https://www.pagina12.com.ar/212309-el-ejercito-de-ocupacion. Acceso: 6 sept. 2019.

ROLÓN, G. Gabriel Rolón, psicoanalista y escritor. [Entrevista a] Alejandro Fantino. Animales sueltos. Buenos Aires: América TV, 8 jun. 2018. 1 video (54min). Publicado en el canal El CulTo ProFano. Disponible en: https://www.youtube.com/ watch?v=hvgmwSbYPbQ. Acceso: 15 marzo 2021.

ROUDINESCO, E. Jacques Lacan \& Co.: a history of psychoanalysis in France, 19251985. Chicago: The University of Chicago Press, 1990.

ROUDINESCO, E. Why psychoanalysis?. New York: Columbia University Press, 2003.

SCHUJMAN, A. Aplicá el método Marie Kondo para ordenar tu vida y tus vínculos. Clarín, Buenos Aires, 28 mayo 2019. Disponible en: https://www.clarin.com/buena-vida/aplica-metodo-marie-kondo-ordenar-vida-vinculos_0_POkKphPE6.html. Acceso: 8 sept. 2019.

SEHINKMAN, D. Políticos al diván: cómo piensan los inconscientes que nos gobiernan. Buenos Aires: Sudamericana, 2014.

SILVERSTEIN, M. Indexical order and the dialectics of sociolinguistic life. Texas Linguistic Forum, [s. l.], v. 36, p. 266-295, 2003.

SILVERSTEIN, M.; URBAN, G. Natural histories of discourse. Chicago: The University of Chicago Press, 1996.

SPIVAK, G. C. In other worlds: essays in cultural politics. New York: Methuen, 1987.

STOLOROW, R. D. Autobiographical and theoretical reflections on the ontological unconscious. Contemporary Psychoanalysis, [s. l.], v. 42, n. 2, p. 233-241, 2006. 
TUTE. Tuterapia. Buenos Aires: Sudamericana, 2012.

TUTE. Humor al diván. Buenos Aires: Sudamericana, 2017.

TUTE EN APA, con "Humor al diván”. Buenos Aires: Asociación Psicoanalitica Argentina, 2018. 1 video (57min). Publicado en el canal Asociación Psicoanalitica Argentina. Disponible en: https://www.youtube.com/watch?v=77-Qgh9914I. Acceso: 23 sept. 2019.

WALKERDINE, V.; LUCEY, H. Democracy in the Kitchen: regulating mothers and socializing daughters. London: Virago, 1989.

ZELIZER, B. The Kennedy assassination: covering the body, the media and the shaping of collective memory. Chicago: The Chicago University Press, 1992.

Recebido: 16/03/2021 Aceito: 29/03/2021 | Received:3/16/2021 Accepted:3/29/2021 